\title{
Thermal Model of Electric Machines with Correction of Critical Parameters
}

\author{
Christoph Holtmann ${ }^{1}$, Frank Rinderknecht ${ }^{1}$, Horst E. Friedrich ${ }^{1}$ \\ ${ }^{1}$ Institute of Vehicle Concepts. German Aerospace Center, Stuttgart, Germany
}

\begin{abstract}
This paper deals with a low to middle order finite volume/lumped capacitance thermal model of an electric machine and the correction of critical parameters. The different parts of the electric machine are divided into sub-volumes called finite volumes or lumped capacitances. From the given characteristic geometry of the electric machine, the thermal resistances to create the system matrix are calculated. The resulting nonlinear equation system is solved for steady state condition for a given current density. The result is compared to experimental measurements allowing the calculation of material correction parameters included in the thermal resistances using the least square method. In a second step an experiment with time dependent current in the stator windings is done. The experiment then is simulated with the time dependent current measured in the experiment using the correction parameters found in the first step. The paper aims to present the possibility to calculate the maximum temperatures very accurately with this method.
\end{abstract}

\section{INTRODUCTION}

In many applications of electric drive systems the time dependent behaviour of the maximum local temperatures in the windings and magnets is of major interest to predict the maximum possible machine load. Especially for electricvehicle applications in which the traction motor can also be used for braking, the question how much kinetic energy can be transformed to electrical and heat energy by the traction-motor has to be answered from the thermal point of view. Especially in the project "Next Generation Car" (NGC) of the German Aerospace Center, where one goal is to reduce the wear and the weight of mechanical friction brakes or even to replace them totally, this question is of major interest.

Models to calculate the thermal behaviour of electrical machines are presented in a lot of publications. A general overview for thermal analysis techniques of electrical machines is shown in [1]. One of the most common used technique is the method of lumped thermal networks used in [2]-[5]. FEA-models are more accurate in terms of a high resolution of the temperature field but only if the heat conductivity and the specific heat is known accurately over the whole domain. Especially in the windings, the area with the highest temperatures, the thermal properties are not known because of enclosures of air in the winding-impregnation, air between the insulation-paper and the windings, the real distribution of the copper wires and many other aspects. The temperature of the surrounding fluid has to be calculated accurately by CFD-analyses to benefit from the FEA-analyses in the solid components compared to lumped thermal analyses. So thermal FEA-analyses are very calculation cost intensive while the accuracy is not higher compared to lumped models. Therefore FEA-calculations have to be verified with experiments just as lumped-thermal models.

The exact opposite compared to a FEA-analyses with high resolution is the method shown in [3]. This method is based on a lumped model with only two to three nodes and has therefore very low computational complexity. However for a correct temperature prediction, the parameters included in the resulting system matrices have to be identified via experiments. Because the parameters can only be extracted from experiments of a real machine with already existing design, this method is not useful to predict the temperatures within a machine design process compared to other lumped models where the system parameters are a result of approximated thermal resistances and heat capacitances. The model in this paper is a higher order model described in [2] but critical parameters for example some heat transfer coefficients and winding resistances are multiplied with correction parameters. The correction parameters are also identified by experiments as in [3] but the parameters of the system matrices are mostly calculated theoretical. Therefore the correction parameters can be used to predict the temperatures of a different machine design within the design process.

March 24, 2017

\section{PROBLEM DESCRIPTION AND METHOD}

The temperature field of classical radial flux machines has to be approximated. The stator of radial flux machines in general have the same characteristic geometry as shown in figure II.1 and II.2. The rotor geometry of a radial flux machine first of all depends on its kind of excitation and can include magnets and or excitation coils in case of a synchronous machine or solid metal bars in case of an asynchronous machine. Most machines of this types can be described with the same geometric parameters of the rotor if the geometry of magnets and the rotor groove for excitation coils are generally included in the rotor model. In the case of a permanent-synchronous machine, the material for the rotor groove is set to steel. This allows to calculate the thermal behaviour of different machine types with one model.

In general, to calculate the thermal behaviour of a system, the non-linear heat-transfer-equation has to be solved.

$$
c_{\mathrm{p}} \frac{\mathrm{d} \vartheta}{\mathrm{d} t}=\nabla \cdot[\lambda \nabla \vartheta]+\dot{q}
$$




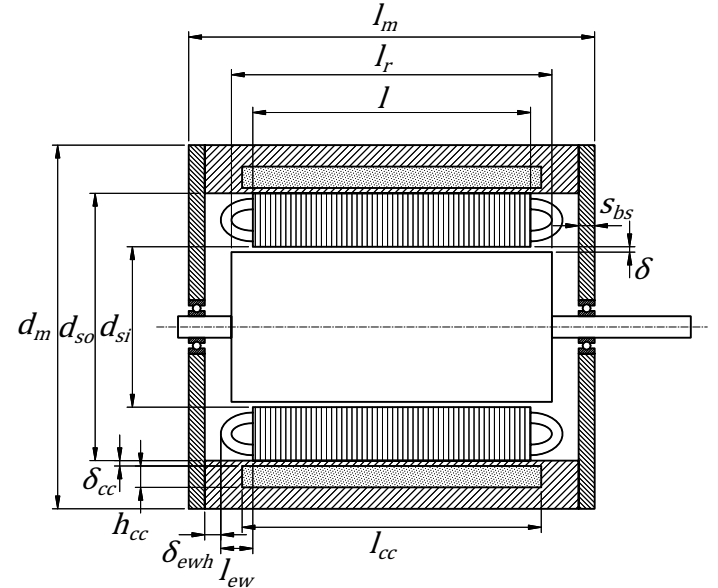

Fig. II.1: Longitudinal section of a radial flux machine with geometric parameters

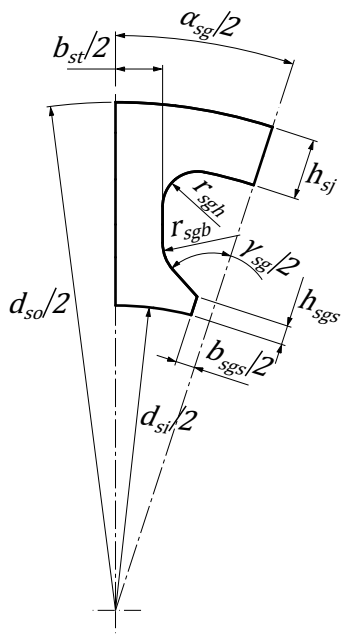

(a) Segment of the stator

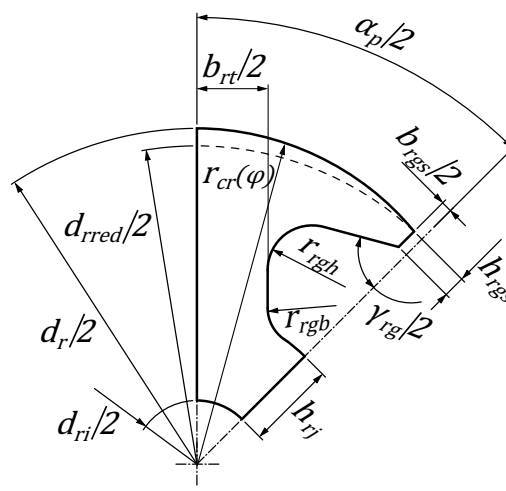

(b) Segment of the rotor
Fig. II.2: Geometric parameters of the stator and rotor

where $\lambda$ is the heat-conductivity, $c_{\mathrm{p}}$ the specific heat and $\dot{q}$ the internal heat-rate. To simplify the problem a finite volume or lumped capacitance model is used. The lumped capacitance model results in the non linear equation system

$$
\frac{\mathrm{d} \vartheta}{\mathrm{d} t}=\frac{1}{C}\left[A(\vartheta) \vartheta+B(\vartheta) \vartheta_{\mathrm{b}}+\dot{Q}\right],
$$

where the matrix $A$ includes the thermal resistances to connect neighboured lumped capacitances and $B$ the thermal resistances to connect the boundary nodes with the boundary conditions.

Figure II.3 shows the calculation precess for the thermal machine model. From the geometrical parameters the heat path and the sub-volumes are calculated to determine the resistances which are included in the system matrix and the heat capacitances respectively. The needed heat-film coefficients first of all depends on the geometry but many of them also on the temperature of the respective surface $\vartheta_{\mathrm{s}}$ because they are a function of the Grashof-number

$$
G r=\frac{g \beta\left(\vartheta_{\mathrm{s}}-\vartheta_{\mathrm{f}}\right) L^{3}}{\nu^{2}} .
$$

. Also the electrical conductivity and therefore the heat rates in the windings depend on the temperature and in a stationary case the calculation is done iteratively. In case of a stationary calculation the iteration loop is repeated till the error between to following steps undertakes a predefined maximum error, whereas in a transient simulation the hole process will be done in every time step using the temperatures form the time step before to calculate the heat-film coefficients and the heat rates.

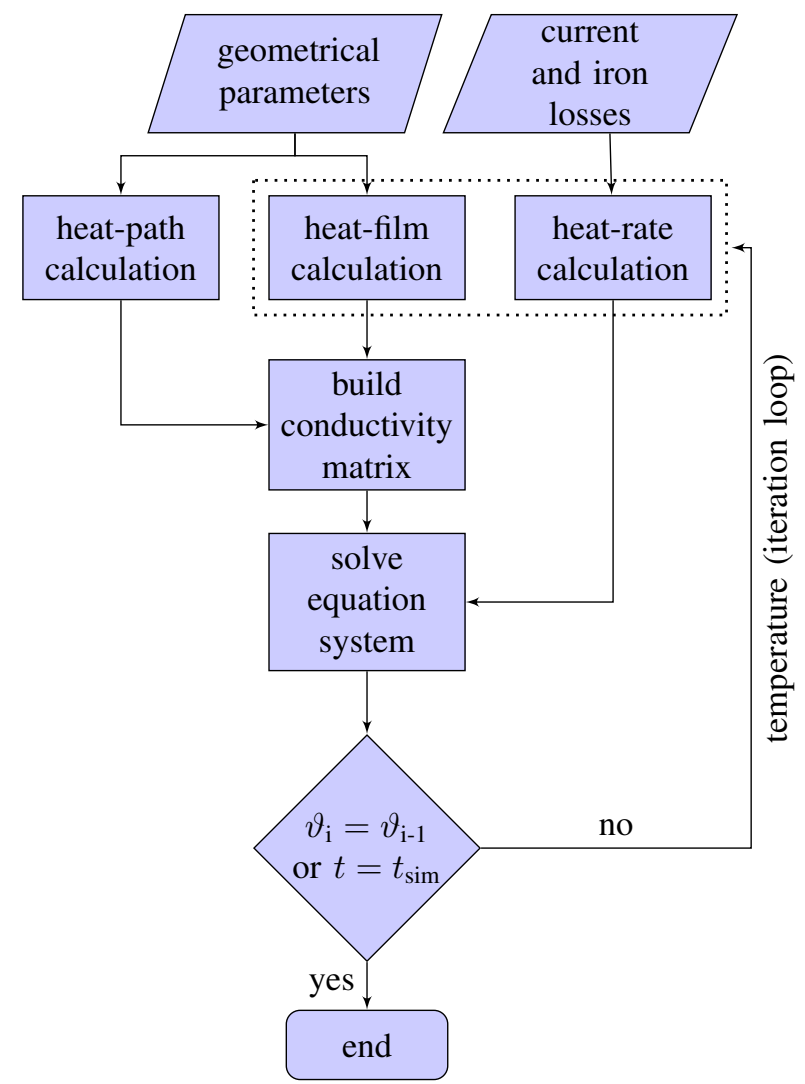

Fig. II.3: Calculation process of the thermal machine model. In case of a stationary calculation the iteration loop is repeated till the error between to following steps undertakes a predefined maximum error. In case of a transient simulation the hole process will be done in every time step using the temperatures form the time step before to calculate the heat-film coefficients and the heat rates

Because the correct thermal parameters mostly are not known, critical parameters are multiplied with correction parameters. These correction-parameters are evaluated with an optimization algorithm while comparing the result of a static calculation with a stationary experiment as shown in figure V.2 in the section verification and results.

\section{THERMAL MODEL}

The machine is divided into sub-volumes as shown in figure III.1a and III.2. The sub-volume model of the stator in the $\mathrm{x}$ y-plane consists of 18 nodes ( 7 winding nodes, 9 lamination 
nodes and 2 nodes of the cooling wall) and the rotor of 7 winding nodes, 1 node of the rotor-groove gap, 1 magnet node, 1 shaft node and 7 lamination nodes. With the assumption of an adiabatic symmetric boundary at $z=0$, every element of the stator and rotor is divided into $N_{\text {zhalf }}$ sub volumes in axial direction (figure III.2). The $N_{\text {zhalf }}$ th elements of the windings inside the stator and rotor (in case of an externally excited machine) are connected to the end winding elements and the $N_{\text {zhalf }}$ 's lamination elements of the stator and rotor are neighboured to the air of the end region. The end- region consist of the bearing shield, the shaft-end, and the air inside the winding area as shown in figure III.6.
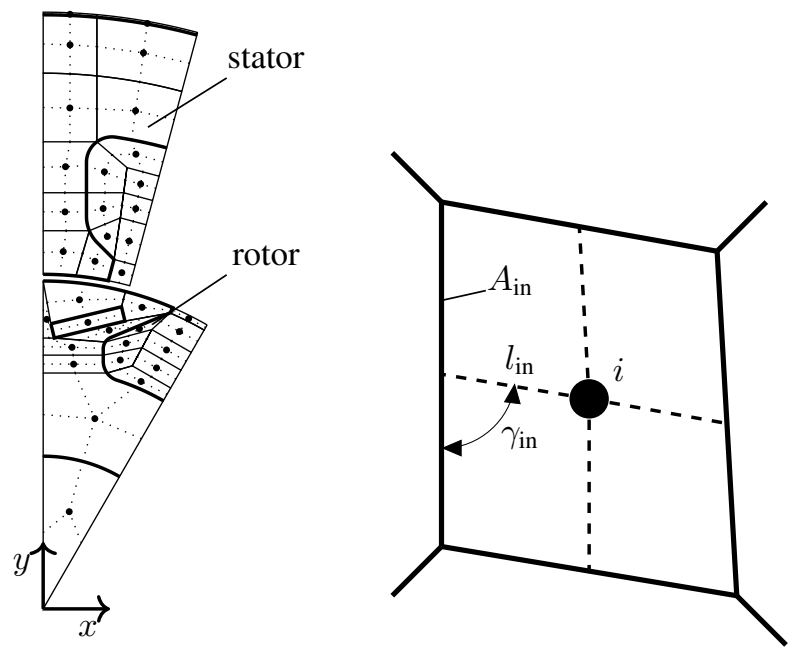

(a) Sub-volumes of the stator and (b) Heat flux paths in one elerotor with inner nodes ment from its node to its border

Fig. III.1: Sub-volumes with heat flux paths

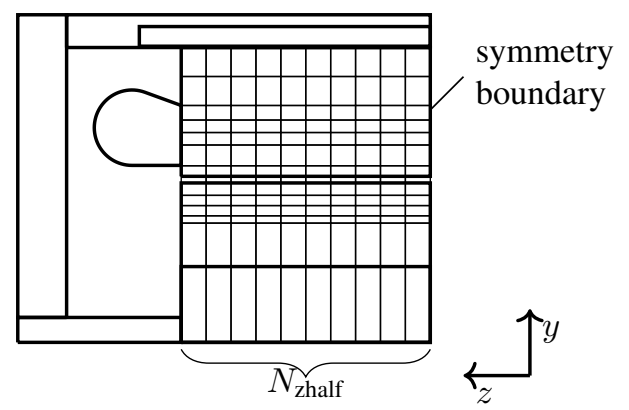

Fig. III.2: $N_{\text {zhalf }}$ sub-volumes of the active machine part in z-direction (axial). Every sub-volume in z-direction is split up into the sub-volumes in the $\mathrm{x}-\mathrm{y}$ plane as shown in figure III.1

The energy balance for one element node $i$ that is connected to $N_{\mathrm{n}}$ neighboured nodes with the index $n$ and to $N_{\mathrm{b}}$ neighboured boundary conditions with the index $b$ as shown in figure III. 3 is

$$
C_{\mathrm{i}} \frac{\mathrm{d} \vartheta_{\mathrm{i}}}{\mathrm{d} t}=\sum_{\mathrm{n}=1}^{N_{\mathrm{n}}} G_{\mathrm{in}} \vartheta_{\mathrm{n}}-\vartheta_{\mathrm{i}} G_{\mathrm{tot}}+\sum_{\mathrm{b}=1}^{N_{\mathrm{b}}} G_{\mathrm{ib}} \vartheta_{\mathrm{b}}+\dot{Q}_{\mathrm{i}}
$$

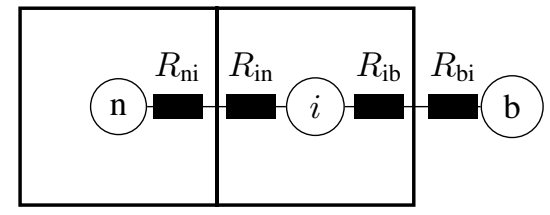

Fig. III.3: One sub-volume node $i$ with one neighboured (inside) node $n$ and one boundary node $b$

, with

$$
G_{\mathrm{tot}}=\sum_{\mathrm{n}=1}^{N_{\mathrm{n}}} \frac{1}{R_{\mathrm{in}}+R_{\mathrm{ni}}}+\sum_{\mathrm{b}=1}^{N_{\mathrm{b}}} \frac{1}{R_{\mathrm{ib}}+R_{\mathrm{bi}}}
$$

and

$$
G_{\text {in }}=\frac{1}{R_{\text {in }}+R_{\mathrm{ni}}} \quad G_{\mathrm{ib}}=\frac{1}{R_{\mathrm{ib}}+R_{\mathrm{bi}}}
$$

where $R_{\text {in }}$ is the inner resistance of element $i$ of the path to the neighbour element $n$ and $R_{\mathrm{ni}}$ is the inner resistance of the neighbour element of the path to the element $i . C_{\mathrm{i}}$ is the total heat capacitance of the element $i$ and $\dot{Q}_{\mathrm{i}}$ the heat generated in the $i^{\prime} t h$ element.

\section{A. thermal resistances}

The thermal resistance of the heat path from one node $i$ to a neighboured node $n$ in a solid material is

$$
R_{\text {in }}+R_{\mathrm{ni}}=\frac{l_{\text {in }}}{\lambda_{\mathrm{i}} A_{\text {in }} \cos \left(\beta_{\mathrm{in}}\right)}+\frac{l_{\mathrm{ni}}}{\lambda_{\mathrm{n}} A_{\mathrm{ni}} \cos \left(\beta_{\mathrm{ni}}\right)},
$$

where $\lambda_{\mathrm{i}}$ and $\lambda_{\mathrm{n}}$ are the heat conductivities, $l_{\mathrm{in}}$ and $l_{\mathrm{ni}}$ are the lengths of the heat path in the respective element, $\beta_{\text {in }}$ and $\beta_{\mathrm{ni}}$ are the complementary angles to $\gamma_{\text {in }}$ shown in figure III.1b and $\gamma_{\text {ni }}$ respectively and $A_{\text {in }}=A_{\text {ni }}$ are the bounding cross-section of the elements. Between neighboured nodes of lamination material and winding an additional resistance of the insulation paper (see figure III.4a) is considered such that the total resistance of the respective winding element is

$$
R_{\text {in }}=\frac{l_{\mathrm{i}}-\delta_{\text {ins }}}{\lambda_{\mathrm{i}} A_{\text {in }}}+\frac{\delta_{\text {ins }}}{\lambda_{\text {ins }} A_{\text {in }}},
$$

. when $i$ is the index of the winding node and $n$ the index of the lamination node.

Because the windings consisting copper of wires surrounded by insulation material and not homogeneous copper a resulting middle heat conductivity has to be calculated. In [6] an analytical model for calculating the thermal resistance of windings is shown. The thermal resistance of one winding layer in one direction is in general a combination of two parallel heat flow paths. The first path goes from one layer to a neighboured layer through air and or impregnation and the second path goes through the copper wire from one layer to a neighboured layer as shown in figure 3 in [6]. Because the machine is two magnitudes longer than the wire diameter, the parallel resistance through the copper wire to a neighboured layer will be neglected in this work. With this simplification a middle heat conductivity in $\mathrm{x}$-y-direction can be calculated 
with equation (19) in [6].

$$
\lambda_{\mathrm{mj}}^{*}=\frac{2}{\alpha}\left(Y+\delta_{\mathrm{imp}}^{*} \frac{Z}{2 \alpha}\right) \quad \text { with } \quad \alpha=1-\delta_{\mathrm{imp}}^{*},
$$

where

$$
\delta_{\text {imp }}^{*}=1-k_{\mathrm{fcu}} \frac{2 \sqrt{3}}{\pi}
$$

and $Y$ and $Z$ are given in [6]. The copper filling factor $k_{\mathrm{fcu}}$ is defined with

$$
k_{\mathrm{fcu}}=\frac{N_{\mathrm{wg}} A_{\mathrm{w}}}{A_{\mathrm{g}}-A_{\text {ins }}}=\frac{N_{\mathrm{wg}} A_{\mathrm{w}}}{A_{g}-l_{\text {ins }} \delta_{\text {ins }}},
$$

where $A_{\mathrm{g}}$ is the groove cross-section without groove-slot, $N_{\mathrm{wg}}$ is the number of winding in one groove, $d_{\mathrm{w}}$ is the wire diameter and $\delta_{\text {ins }}$ and $l_{\text {ins }}$ is the thickness and length of the insulation paper as illustrated in III.4a. The dashed line in Figure III.5 shows the dimensionless heat conductivity $\lambda_{\mathrm{m}}{ }^{*}=\lambda_{\mathrm{m}} / \lambda_{\text {imp }}$ as a function of the copper filling factor. It can be seen that equation (9) for $k_{\mathrm{fcu}}<0.3$ delivers a middle heat conductivity that is smaller than the conductivity of the impregnation $\left(\lambda_{\mathrm{mj}}{ }^{*}<1\right)$ illustrated in figure III.5 with the dash-dotted line. So equation (9) is not valid for small filling factors and therefore in addition another model that is shown in figure III.4b is used. This model is based on the following approach

$$
R_{\mathrm{m}}=\frac{L}{\lambda_{\mathrm{m}} L^{2}}=\frac{\left(R_{\mathrm{cu}}+R_{\mathrm{imp} 1}\right) R_{\mathrm{imp} 2}}{R_{\mathrm{cu}}+R_{\mathrm{imp} 1}+R_{\mathrm{imp} 2}},
$$

where $L$ is the size of the total square and $k_{\mathrm{fcu}}=\sqrt{l^{2} / L^{2}}$ when $l$ is the length of the square with the conductivity of copper $\lambda_{\mathrm{cu}}$. With this assumptions the middle heat conductivity results in

$$
\lambda_{\mathrm{ms}}^{*}=1+\sqrt{k_{\mathrm{fcu}}}\left[\frac{1}{1+\sqrt{k_{\mathrm{fcu}}}\left(\frac{\lambda_{\mathrm{imp}}}{\lambda_{\mathrm{cu}}}-1\right)}-1\right]
$$

and is shown as the doted line in figure III.5. It is assumed that the model of [6] gives better results for the middle heat conductivity at high copper filling factors compared to the simple model. So the middle heat conductivity is weighted with the copper filling factor $k_{\mathrm{cu}}$ such that $\lambda_{\mathrm{m}}{ }^{*}=\lambda_{\mathrm{ms}}{ }^{*}=1$ for $k_{\mathrm{fcu}}=0$ and $\lambda_{\mathrm{m}}{ }^{*}=\lambda_{\mathrm{mj}}{ }^{*}$ for $k_{\mathrm{fcu}}=1$.

$$
\lambda_{\mathrm{m}}{ }^{*}=\lambda_{\mathrm{ms}}{ }^{*}\left(1-k_{\mathrm{fcu}}\right)+\lambda_{\mathrm{mj}}{ }^{*} k_{\mathrm{fcu}}
$$

If one element $i$ is neighboured to a boundary-node or element-node related to a fluid, the neighboured resistance is

$$
R_{\mathrm{ni}}=\frac{1}{\alpha_{\mathrm{ni}} A_{\mathrm{in}}},
$$

where $\alpha_{\mathrm{ni}}$ is the heat film coefficient to the neighboured fluid.

\section{B. Heat film coefficients}

The heat film coefficients have a strong influence on the error between a lumped thermal network and experimental results. To achieve a small error valid Nusselt-correlations are needed for every heat film coefficient $\alpha$ for the different

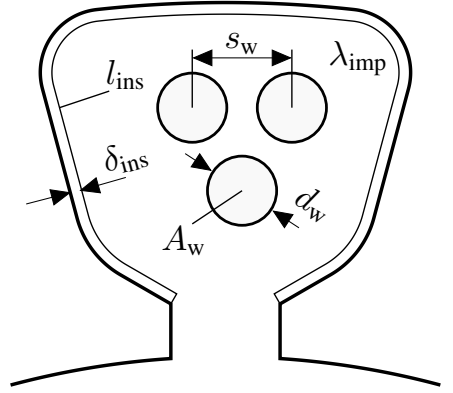

(a) Stator groove

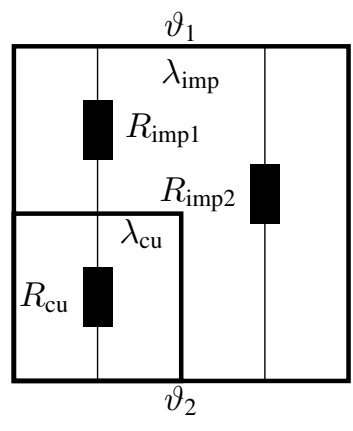

(b) Simple model
Fig. III.4: Stator groove with insulation-paper of the thickness $\delta_{\text {ins }}$ and the length $l_{\text {ins }}$ and orthogonal arranged wires with the cross-section $A_{\mathrm{w}}$ (a) and simple model to approximate the middle heat conductivity in the groove (b)

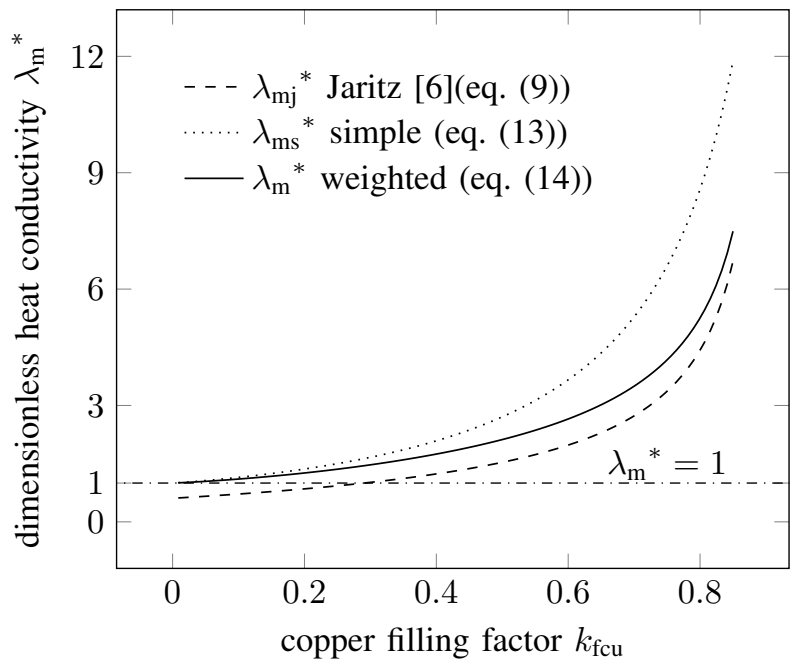

Fig. III.5: Comparison of calculation methods for the (dimensionless) middle heat conductivity as a function of the copper filling factor. Model from [6] (dashed line), simple model equation (13) corresponding to III.4b (dotted line) and weighted function (13) with the copper filling factor as weight parameter (solid line)

machine areas as shown in figure III.6. In general, the heat film coefficients $\alpha$ are calculated with Nusselt-correlations with the well known definition $N u=\alpha d / \lambda$ where $d$ is a characteristic length and $\lambda$ the heat conductivity of the fluid. The references for the Nusselt-correlations used to calculate the heat film coefficients are given in table III.1. The Nusseltcorrelation for the airgap is given in [7] and [8] and its known as the correlation by Becker and Kaye [9]. Compared to [9], [10] gives the Nusselt-correlation in the airgap for a rotational movement and a flow in axial direction. The influence of slots in the rotor like in switched reluctance machines is analysed numerically by [8]. In this paper we use the correlation from [9] and [10] with the correlation for the turbulent case given by equation (27) in [11]. The heat film coefficient $\alpha_{\text {bso }}$ of the bearing shield to the outside is calculated with the correlation for an vertical plate as a result of free convection given in 


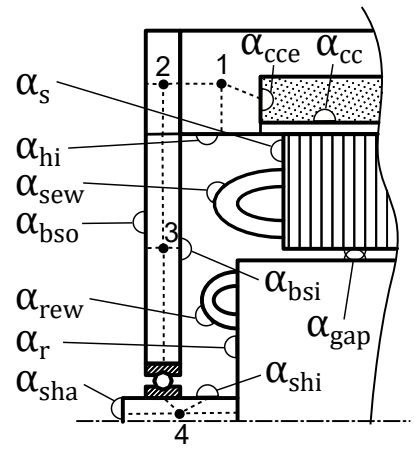

Fig. III.6: End area with bearing shield of an electrical machine and all relevant heat film coefficients $\alpha$ for the thermal calculation

[12]. This correlation is also used for the heat film of the stator-end $\alpha_{\mathrm{s}}$ for mixed convection with the forced convection component caused by the flow rate of the rotating rotor-end (rotating plate). The flow rate $\dot{V}$ at the outer edges of a rotating plate with the outer radius $R$ and the angular velocity $\omega$ is given from equation (4) in [15].

$$
\dot{V}=\frac{0.886 \pi R^{3} \omega}{\sqrt{\frac{\omega R^{2}}{\nu}}}
$$

To approximate the velocity over the stator-end needed for the Nusselt-correlation these flow rate is divided by the middle surface area corresponding to the middle stator radius and the half space between the stator-end and the bearing shield.

$$
v=\frac{\dot{V} 4}{\pi\left(d_{\mathrm{so}}+d_{\mathrm{si}}\right)\left(l_{m}-l-2 s_{\mathrm{bs}}\right)}
$$

The method to approximate the heat film coefficient of the stator end is also used to calculate the heat film coefficient $\alpha_{\mathrm{bsi}}$ of the bearing shield to the inside, while using the middle radius of the bearing shield to calculate the forced flow velocity over the bearing shield. To determine the heat film coefficient of the stator-winding-head, the stator-windinghead is abstracted as a half sphere with mixed convection given in [12] while using the velocity (17). In [13] the correlation for the heat film $\alpha_{\mathrm{r}}$ of the rotor surface in a closed cavity is given also as a function of the gap ratios $G$. Corresponding to figure II.1 here $G$ is

$$
G=\frac{l_{\mathrm{m}}-l_{\mathrm{r}}-2 s_{\mathrm{bs}}}{d_{\mathrm{si}}} .
$$

The heat transfer from the winding head of the rotor is mostly a result of forced convection but in general calculated as a mixed convection, especially at slow speeds. So for the approximation of $\alpha_{\text {rew }}$ the end windings of the rotor are modelled as half spheres moving with the velocity

$$
v=\omega\left(d_{\mathrm{ri}} / 2+h_{\mathrm{rj}}+d_{\mathrm{r}} / 2\right) / 2
$$

with the parameters corresponding to figure II.1, while using the Nusselt-correlation for mixed convection of a sphere in [12]. For the shaft $\alpha_{\text {shi }}$ the Nusselt-correlation can be obtained from table 2 in [2] for a rotating cylinder. The heat transfer in the cooling channel is approximated as a simple channel-flow with the Nusselt-correlation given in [12].

TABLE III.1: References for Nusselt-correlations corresponding to figure III.6

\begin{tabular}{llcc}
\hline $\begin{array}{l}\text { heat } \\
\text { film } \\
\text { coeff. }\end{array}$ & part/area & (equations from ref.) & [reference](sec.) \\
\hline & & & \\
$\alpha_{\text {gap }}$ & airgap & $(3),(4)$ & {$[7][9]$} \\
$\alpha_{\text {gap }}$ & airgap & $(35),(36)$ & {$[10]$} \\
$\alpha_{\text {gap }}$ & airgap & $(38)$ & {$[11]$} \\
\hline$\alpha_{\text {bso }}$ & bear. sh. out & $(12),(13)$ & {$[12](\mathrm{Fa} 2)$} \\
\hline$\alpha_{\text {bsi }}$ & bear--shield in. & $(12),(13)$ & {$[12](\mathrm{Fa} 2)$} \\
$\alpha_{\text {bsi }}$ & bear--shield in. & $(9)$ & {$[12](\mathrm{Fe} 5)$} \\
$\alpha_{\text {bsi }}$ & bear--shield in. & $(17),(18)$ & {$[12](\mathrm{Fe} 6)$} \\
\hline$\alpha_{\mathrm{s}}$ & stator end & $(12),(13)$ & {$[12](\mathrm{Fa} 2)$} \\
$\alpha_{\mathrm{s}}$ & stator end & $(9)$ & {$[12](\mathrm{Fe} 5)$} \\
$\alpha_{\mathrm{s}}$ & stator end & $(17),(18)$ & {$[12](\mathrm{Fe} 6)$} \\
\hline$\alpha_{\text {sew }}$ & stator end-wind. & $(24),(25),(26),(27)$ & {$[12](\mathrm{Fe} 8)$} \\
$\alpha_{\text {sew }}$ & stator end-wind. & $(9)$ & {$[12](\mathrm{Fe} 5)$} \\
\hline$\alpha_{\mathrm{r}}$ & rotor end & $(12),(13)$ & {$[12](\mathrm{Fa} 2)$} \\
$\alpha_{\mathrm{r}}$ & rotor end & $(-)$ & {$[11](\mathrm{table} \mathrm{II)}$} \\
\hline$\alpha_{\text {rew }}$ & rotor end-wind. & $(24),(25),(26),(27)$ & {$[12](\mathrm{Fe} 8)$} \\
$\alpha_{\text {rew }}$ & rotor end-wind. & $(9)$ & {$[12](\mathrm{Fe} 5)$} \\
\hline$\alpha_{\text {cc }}$ & cooling channel & $(36),(38),(39)$ & {$[12](\mathrm{GB} 2.3 .1)$} \\
$\alpha_{\text {cc }}$ & cooling channel & $(29),(30),(32),(33)$ & {$[12](\mathrm{GA} \mathrm{4.2)}$} \\
\hline$\alpha_{\text {sho }}$ & shaft outside & $(12),(13)$ & {$[12](\mathrm{Fa} 2)$} \\
\hline$\alpha_{\text {shi }}$ & shaft inside & $(-)$ & {$[2](\mathrm{table} \mathrm{IV)}$} \\
\hline & & & \\
\hline & & & \\
\hline
\end{tabular}

\section{Heat sources}

The heat loss in an electrical machine is the sum of copper losses in the windings and iron losses in the laminations.

The ohmic loss in the $i^{\prime}$ th element of the windings with the resistance $R_{\text {wie }}$ of a single wire with the length $l_{\text {ei }}$ of the element due to the current $I$ is

$$
P_{\text {wei }}=N_{\text {wei }} I^{2} R_{\text {wie }}=\frac{N_{\text {wei }} N_{\text {wg }} I^{2} l_{\text {ei }}}{\sigma_{\text {cui }} k_{\text {fcu }}\left(A_{g}-A_{\text {ins }}\right)}
$$

, where the $N_{\text {wei }}$ is the number of copper wires in the $i^{\prime}$ th element with the cross-section $A_{\mathrm{ei}}$

$$
N_{\text {wei }}=N_{\text {wg }} \frac{A_{\text {ei }}}{A_{\mathrm{g}}-A_{\text {ins }}}
$$

and $l_{\text {ei }}$ is the length of $i$ 'th element. The electrical conductivity $\sigma_{\text {cui }}$ of the copper wires strongly depends on the temperature $\vartheta_{\mathrm{i}}$.

$$
\sigma_{\text {cui }}=\frac{1}{\rho_{\text {cu20 }}\left[1+\alpha_{\text {cu }}\left(\vartheta_{\mathrm{i}}-20^{\circ} c\right)\right]}
$$

The temperature coefficient $\alpha_{\mathrm{cu}}$ has a value of $\alpha_{\mathrm{cu}}=3.9$. $10^{-} 3 K^{-1}$.

The iron losses are calculated with the Steinmetz equation given in [16].

$$
P_{\text {ironi }}=V_{\mathrm{i}}\left(C_{\mathrm{m}} f^{\alpha} \hat{B}_{\mathrm{i}}^{\beta}+C_{2} f^{2} \hat{B}_{\mathrm{i}}^{2}\right)
$$


Where $\hat{B}_{\mathrm{i}}$ is the Amplitude of the magnetic flux density, $f$ the pulsating frequency of the magnetic flux, $V_{\mathrm{i}}$ is the volume of the element $i$ and $\alpha, \beta, C_{\mathrm{m}}$ and $C_{2}$ are material based parameters.

\section{EXPERIMENTAL SETUP}

To validate the presented thermal model a small experimental machine for thermal experiments is assembled as illustrated in figure IV.1. It's geometrical parameters shown in table IV.1 and the material parameters in IV.2. Temperatures are measured at the end windings, the cooling channel, the inner wall of the cooling channel and at different places in the stator lamination as shown in figure IV.2. The winding temperature inside the stator is not measured directly.
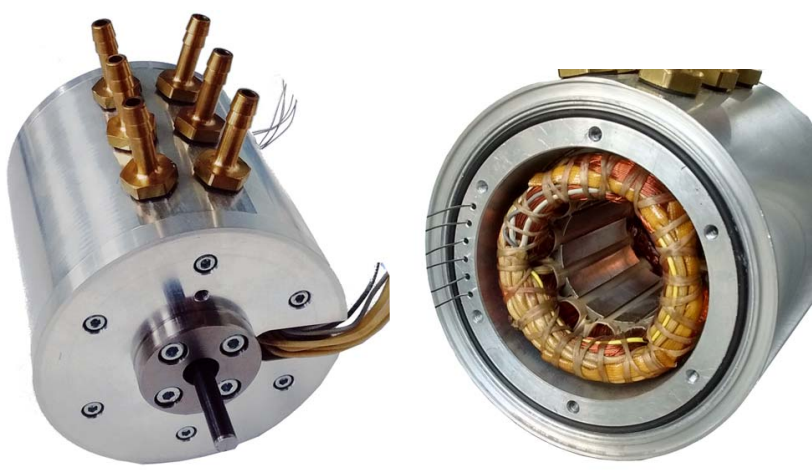

(a) Machine for thermal experi- (b) Machine without bearing ments shield

Fig. IV.1: Experimental machine

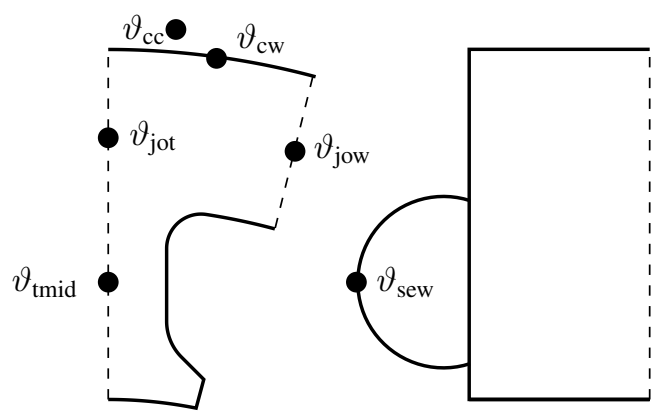

Fig. IV.2: Position of thermocouples in the stator $\left(\vartheta_{\text {tmid }}, \vartheta_{\text {jot }}, \vartheta_{\text {jow }}\right)$, at the end-winding $\vartheta_{\text {sew }}$, in the wall of the cooling channel $\vartheta_{\text {cw }}$ and in the cooling channel $\vartheta_{\mathrm{cc}}$.

Because the specific resistance depends on the temperature, the total ohmic loss in the model and the experiment should be equal if the model is valid. It has to be pointed out that if the total ohmic loss are equal, the temperature distribution in the windings can still be different. But if the temperature at the end windings in the experiment and the model is also equal, the temperature distribution in the windings should be comparable. In the thermal experiment a dc-current is applied to the machine which is measured with a hall-sensor.
TABLE IV.1: Geometric parameters of experimental machine corresponding to figure II.1 and II.2

\begin{tabular}{lccc}
\hline parameter & symbol & value & unit \\
\hline & $d_{\mathrm{m}}$ & $90 e-3$ & {$[\mathrm{~m}]$} \\
Machine diameter & $l_{\mathrm{m}}$ & $92 e-3$ & {$[\mathrm{~m}]$} \\
Machine length & $d_{\mathrm{si}}$ & $33 e-3$ & {$[\mathrm{~m}]$} \\
Stator bore diameter & $\delta$ & $0.75 e-3$ & {$[\mathrm{~m}]$} \\
airgap & $d_{\mathrm{so}}$ & $60 e-3$ & {$[\mathrm{~m}]$} \\
Stator outer diameter & $l$ & $40 e-3$ & {$[\mathrm{~m}]$} \\
Stator length & $l_{\mathrm{r}}$ & $40 e-3$ & {$[\mathrm{~m}]$} \\
rotor length & $s_{\mathrm{ss}}$ & $6 e-3$ & {$[\mathrm{~m}]$} \\
thickness bearing shield & $\delta_{\mathrm{cc}}$ & $3 e-3$ & {$[\mathrm{~m}]$} \\
thickness cooling wall & $l_{\mathrm{cc}}$ & $64 e-3$ & {$[\mathrm{~m}]$} \\
length cooling channel & $h_{\mathrm{cc}}$ & $7 e-3$ & {$[\mathrm{~m}]$} \\
thickness cooling channel & $l_{\mathrm{ew}}$ & $16.5 e-3$ & {$[\mathrm{~m}]$} \\
length winding head & $N$ & 12 & {$[1]$} \\
& $N$ & 150 & {$[\mathrm{deg}]$} \\
Number stator grooves & $\gamma_{\mathrm{sg}}$ & $2.7 e-3$ & {$[\mathrm{~m}]$} \\
stator groove base angle & $b_{\mathrm{st}}$ & $4.4 e-3$ & {$[\mathrm{~m}]$} \\
width stator tooth & $b_{\mathrm{sj}}$ & $4 e-3$ & {$[\mathrm{~m}]$} \\
hight stator joke & $b_{\mathrm{sgs}}$ & $0.8 e-3$ & {$[\mathrm{~m}]$} \\
width groove slot stator & $h_{\mathrm{sgs}}$ & $0.5 e-3$ & {$[\mathrm{~m}]$} \\
hight groove slot stator & $r_{\mathrm{sgb}}$ & $1 e-3$ & {$[\mathrm{~m}]$} \\
groove base radius stator & $r_{\mathrm{sgh}}$ & 360 & {$[1]$} \\
groove base radius stator & $N_{\mathrm{wg}}$ & $0.28 e^{-} 3$ & {$[\mathrm{~m}]$} \\
Number of wires in one groove & $d_{\mathrm{w}}$ & & \\
wire diameter & & & \\
\hline & & &
\end{tabular}

TABLE IV.2: Material parameters of the experimental machine

\begin{tabular}{|c|c|c|c|}
\hline part/parameter & symbol & value & unit \\
\hline \multicolumn{4}{|c|}{ Laminations (M470-50a) } \\
\hline density & $\rho_{\mathrm{l}}$ & 7600 & {$\left[\mathrm{~kg} \mathrm{~m}^{-3}\right]$} \\
\hline heat capacitance & $c_{\mathrm{pl}}$ & 460 & {$\left[\mathrm{~J} \mathrm{~kg}^{-1} \mathrm{~K}^{-1}\right]$} \\
\hline conductivity (h) & $\lambda_{\mathrm{l}}$ & 30.3 & {$\left[\mathrm{~W} \mathrm{~m}{ }^{-1} \mathrm{~K}^{-1}\right]$} \\
\hline \multicolumn{4}{|l|}{ Windings } \\
\hline density & $\rho_{w}$ & 8920 & {$\left[\mathrm{~kg} \mathrm{~m}^{-3}\right]$} \\
\hline heat capacitance & $c_{\mathrm{pw}}$ & 460 & {$\left[\mathrm{~J} \mathrm{~kg}^{-1} \mathrm{~K}^{-1}\right]$} \\
\hline conductivity (h) & $\lambda_{\mathrm{w}}$ & 400 & {$\left[\mathrm{~W} \mathrm{~m}{ }^{-1} \mathrm{~K}^{-1}\right]$} \\
\hline conductivity (el) & $\sigma_{\mathrm{w}}$ & $58.5 e^{6}$ & {$\left[\mathrm{~S} \mathrm{~m}^{-1}\right]$} \\
\hline temp.- coeff. & $\alpha_{\mathrm{w}}$ & $3.9 e-3$ & {$\left[\mathrm{~K}^{-1}\right]$} \\
\hline \multicolumn{4}{|c|}{ Winding impregnation (assumed) } \\
\hline density & $\rho_{\text {imp }}$ & 1260 & {$\left[\mathrm{~kg} \mathrm{~m}^{-3}\right]$} \\
\hline heat capacitance & $c_{\text {pimp }}$ & 1250 & {$\left[\mathrm{~J} \mathrm{~kg}^{-1} \mathrm{~K}^{-1}\right]$} \\
\hline conductivity (h) & $\lambda_{\text {imp }}$ & 0.25 & {$\left[\mathrm{~W} \mathrm{~m} \mathrm{~m}^{-1} \mathrm{~K}^{-1}\right]$} \\
\hline \multicolumn{4}{|c|}{ Winding insulation paper (assumed) } \\
\hline density & $\rho_{\mathrm{imp}}$ & 1000 & {$\left[\mathrm{~kg} \mathrm{~m}^{-3}\right]$} \\
\hline heat capacitance & $c_{\text {pimp }}$ & 1000 & {$\left[\mathrm{~J} \mathrm{~kg}^{-1} \mathrm{~K}^{-1}\right]$} \\
\hline conductivity (h) & $\lambda_{\text {imp }}$ & 0.14 & {$\left[\mathrm{~W} \mathrm{~m} \mathrm{~m}^{-1} \mathrm{~K}^{-1}\right]$} \\
\hline \multicolumn{4}{|c|}{ Housing parts (aluminium) } \\
\hline density & $\rho_{\mathrm{h}}$ & 2700 & {$\left[\mathrm{~kg} \mathrm{~m}^{-3}\right]$} \\
\hline heat capacitance & $c_{\mathrm{ph}}$ & 1106 & {$\left[\mathrm{~J} \mathrm{~kg}^{-1} \mathrm{~K}^{-1}\right]$} \\
\hline conductivity (h) & $\lambda_{\mathrm{h}}$ & 130 & {$\left[\mathrm{~W} \mathrm{~m}{ }^{-1} \mathrm{~K}^{-1}\right]$} \\
\hline
\end{tabular}




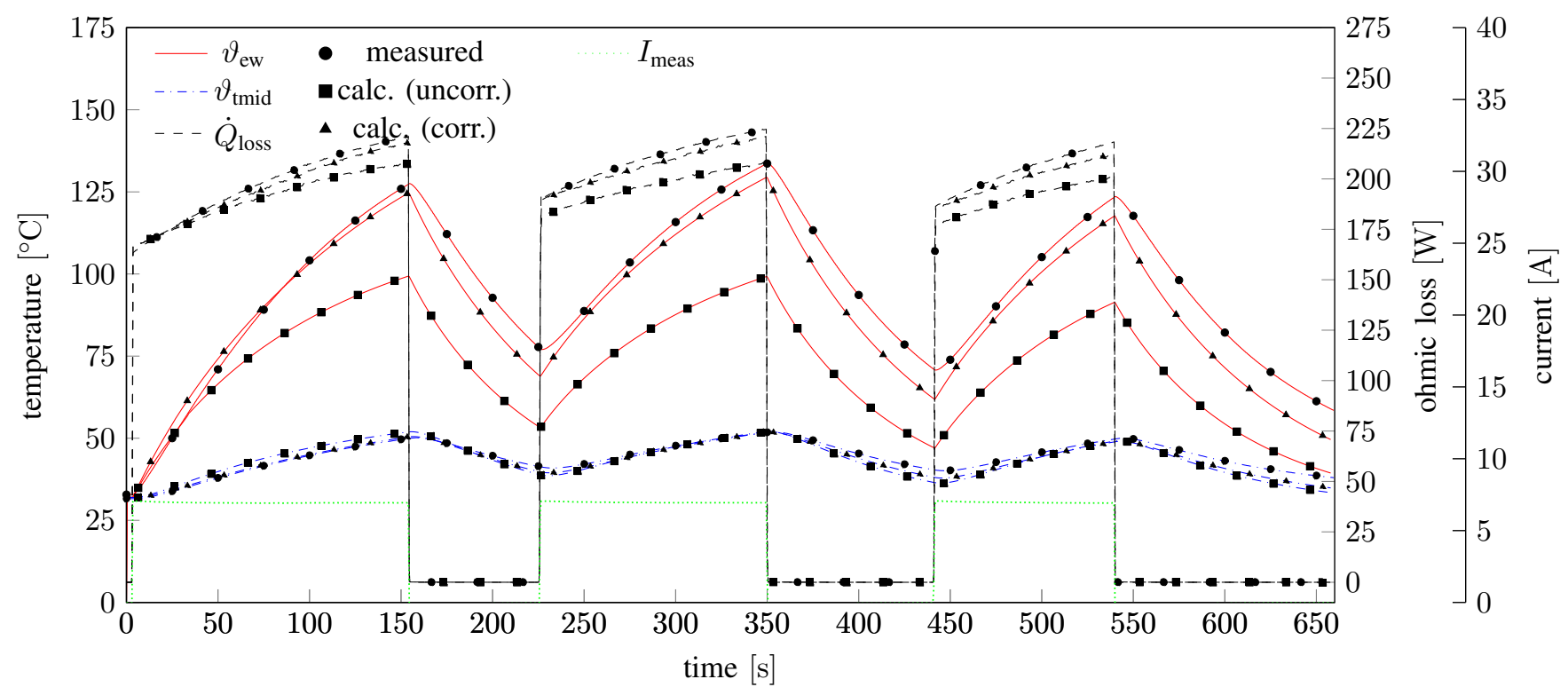

Fig. IV.3: Transient measured and calculated end-winding temperature $\vartheta_{\text {ew }}$, inner stator-tooth temperature $\vartheta_{\text {tmid }}$ and ohmic loss $\dot{Q}_{\text {loss }}$. The markers show if the respective value were measured, calculated with uncorrected parameters or calculated with corrected paramters

\section{VERIFICATION AND RESUlTS}

In a first experiment the total power applied to the machine and the temperatures are measured at constant current and zero speed $n=0$, until the stationary condition is reached. The current measured at this stationary condition is applied as the input current into the static model. The result is shown in figure V.1 named as calculated (uncorrected). It can be seen that the temperatures, in the tooth $\vartheta_{\text {tmid }}$, in the stator joke above the winding $\vartheta_{\text {jow }}$ and in the stator joke above the tooth $\vartheta_{\text {jot }}$ have a maximum error of $4^{\circ} \mathrm{C}$.

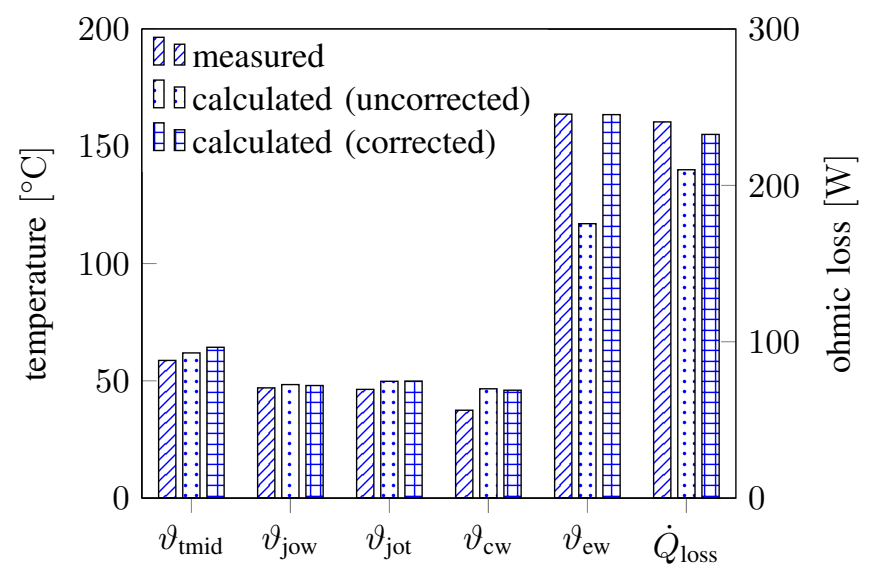

Fig. V.1: Stationary temperatures and ohmic loss, without correction-parameters calculated and with correction parameters compared to measurements

The temperature at the end-winding calculated with the assumed material parameters is $46^{\circ} \mathrm{C}$ lower compared to the experiment. Therefore the ohmic loss is $30 \mathrm{~W}$ lower, because the conductivity of the windings depends on their temperature.
These errors first of all are caused by inaccurate assumptions of the material parameters (and conditions) of the winding impregnation and winding insulation shown in table IV.2.

The most sensitive thermal resistances are the ones where the temperature gradient gets very high. This is the case in the windings and especially in the insulation paper because the heat conductivity of the impregnation-resin and the insulation paper are in the magnitude of air, especially the resulting resistance in these parts are very sensitive to the temperature distribution. So two of four correction parameters that are related to the groove-area such as the thermal resistances will be modified with corrected heat conductivities.

$$
\lambda_{\text {cimp }}=c_{\text {imp }} \lambda_{\text {imp }} \quad \text { and } \quad \lambda_{\text {cins }}=c_{\text {ins }} \lambda_{\text {ins }}
$$

The other two critical thermal resistances are the heat filmresistance at the end-windings and the heat film resistance in the cooling channel. Related to figure III.6 and table III.1 the Nusselt-Number for the end-windings and the cooling-channel is corrected.

$$
N u_{\text {csew }}=c_{\text {sew }} N u_{\text {sew }} \text { and } \quad N u_{\text {ccc }}=c_{\text {cc }} N u_{\text {cc }}
$$

In an optimization algorithm the correction parameters especially for the heat conductivity of the winding insulation and impregnation (in equation (24) and (25)) and the correction parameters of the Nusselt-numbers for the heat film in the cooling channel and the end-winding, are evaluated such that the total square error $E r r^{2}$ gets minimized for the static case.

$$
E r r^{2}=\frac{1}{6}\left[\frac{1}{\vartheta_{\text {ref }}^{2}} \sum_{\text {im=1 }}^{i m=5}\left(\triangle \vartheta_{\text {im }}\right)^{2}+\frac{1}{\dot{Q}_{\text {ref }}^{2}}\left(\triangle \dot{Q}_{\text {loss }}\right)^{2}\right],
$$

where $\triangle \vartheta_{\text {im }}$ is the difference between the calculated and measured temperatures shown in IV.2 and $\triangle \dot{Q}_{\text {loss }}$ is the error 
of the ohmic loss. Because the error is the sum of temperatures and a heat loss, the errors are related to reference values $\vartheta_{\text {ref }}$ and $\dot{Q}_{\text {ref. }}$. Figure V.2 how the process for investigating the correction parameters. The optimization algorithm is based on a hill-climbing method and iteratively chooses correction parameters for the static simulation such that the error gets minimized. The result of the error minimization is shown in

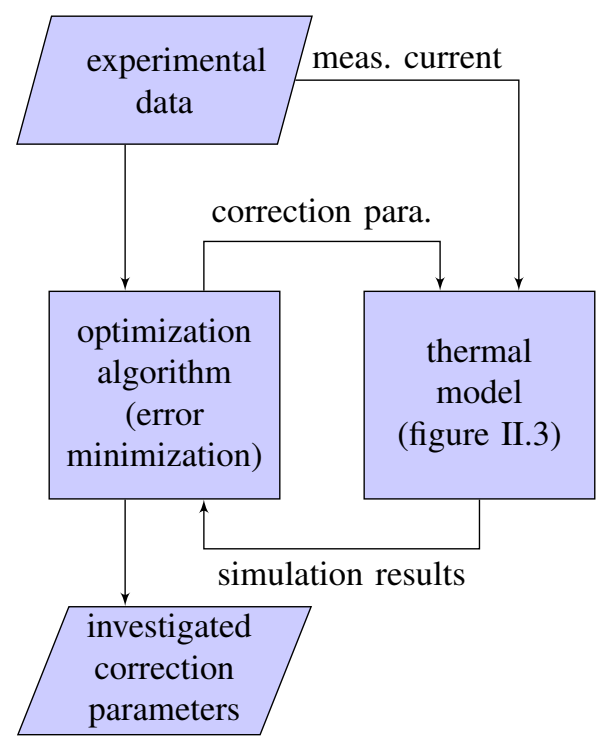

Fig. V.2: evaluation process for the correction parameters

figure V.1 with the bars called calculated (corrected). As it can be seen the error of the end-winding temperature $\vartheta_{\text {ew }}$ is reduced from $46^{\circ} \mathrm{C}$ to nearly zero and the error of the ohmic loss from $30 \mathrm{~W}$ to $8 \mathrm{~W}$. The correction-parameters evaluated for this result are $c_{\mathrm{imp}}=0.69, c_{\mathrm{ins}}=0.625, c_{\mathrm{sew}}=0.33$ and $c_{\mathrm{cc}}=3$. That means, that the effective heat resistance of the windings is 1.54 times higher and that of the insulation 1.6 times higher than expected. The Nusselt-Correlations for this model has to be corrected by a factor of 3 in case of the cooling channel and by a factor of 0.33 in the case of the end-windings.

With the correction-parameters a transient simulation is done with the current measured in an dynamic experiment $I_{\text {meas }}$. The result of the dynamic experiment and its transient simulation is shown in figure IV.3. Whithout the evaluated correction-parameters the maximum error of the end-winding temperature is about $45^{\circ} \mathrm{C}$ and the ohmic loss error is $25 \mathrm{~W}$ compared to the experiment. With correction parameters the maximum error is reduced to $10^{\circ} \mathrm{C}$ in case of the end-winding temperature and to $5 \mathrm{~W}$ for the ohmic loss.

\section{CONCLUSION}

The present model combined with the method to evaluate correction-parameters, allows to predict the temperatures of a radial flux machine in a transient simulation with reasonable accuracy. It has to be pointed out that the correction parameters, do also correct discretisation errors and systematic measurement errors. The bandage of the end-windings (see figure
IV.1) had not been considered in this work which also result in an error between the model an the measurement. In further experiments and simulations with other machine designs, it has to be evaluated how the correction parameters evaluated for one design can be applied for other designs, especially for the Nusselt-correlations. However once the correction parameters had been evaluated with a stationary experiment, the model allows to calculate the maximum allowable current in a machine without overheating it. In future works the model can be implemented in a transient braking test simulation to investigate optimal machine load characteristics for a minimal wear of the friction brakes without overheating the machine, and the use of an additional eddy current brake.

\section{REFERENCES}

[1] Boglietti, Aldo, et al. "Evolution and modern approaches for thermal analysis of electrical machines." Industrial Electronics, IEEE Transactions on 56.3 (2009): 871-882.

[2] Bornschlegell, Augusto Salomao, et al. "Thermal optimization of a high-power salient-pole electrical machine.” Industrial Electronics, IEEE Transactions on 60.5 (2013): 1734-1746.

[3] Huber, Thomas, William Peters, and Joachim Bocker. "Monitoring critical temperatures in permanent magnet synchronous motors using low-order thermal models." Power Electronics Conference (IPEC-Hiroshima 2014ECCE-ASIA), 2014 International. IEEE, 2014.

[4] Kylander, Gunnar. Thermal modelling of small cage induction motors. Chalmers University of Technology, 1995.

[5] Nerg, Janne, Marko Rilla, and Juha Pyrhonen. "Thermal analysis of radial-flux electrical machines with a high power density." Industrial Electronics, IEEE Transactions on 55.10 (2008): 3543-3554.

[6] Jaritz, Michael, and Juergen Biela. "Analytical model for the thermal resistance of windings consisting of solid or litz wire." Power Electronics and Applications (EPE), 2013 15th European Conference on. IEEE, 2013.

[7] Jiang, Wenying, and Thomas M. Jahns. "Development of efficient electromagnetic-thermal coupled model of electric machines based on finite element analysis." Electric Machines Drives Conference (IEMDC), 2013 IEEE International. IEEE, 2013.

[8] Romanazzi, Pietro, and David A. Howey. "Air-gap convection in a switched reluctance machine." Ecological Vehicles and Renewable Energies (EVER), 2015 Tenth International Conference on. IEEE, 2015.

[9] Becker, K. M., and Joseph Kaye. "The influence of a radial temperature gradient on the instability of fluid flow in an annulus with an inner rotating cylinder." Journal of Heat Transfer 84.2 (1962): 106-110.

[10] Simmers, D. A., and J. E. R. Coney. "A Reynolds analogy solution for the heat transfer characteristics of combined Taylor vortex and axial flows." International Journal of Heat and Mass Transfer 22.5 (1979): 679689

[11] Howey, David A., Peter Childs, and Andrew S. Holmes. "Air-gap convection in rotating electrical machines." Industrial Electronics, IEEE Transactions on 59.3 (2012): 1367-1375.

[12] Wrmeatlas, V. D. I. "Verein Deutscher Ingenieure." Springer Verlag, Berlin, Heidelberg, New York 2 (2006): 4.

[13] Boutarfa, Rachid, and Souad Harmand. "Local convective heat transfer for laminar and turbulent flow in a rotor-stator system." Experiments in Fluids 38.2 (2005): 209-221.

[14] Ozerdem, Bari. "Measurement of convective heat transfer coefficient for a horizontal cylinder rotating in quiescent air." International communications in heat and mass transfer 27.3 (2000): 389-395.

[15] Will, Bjrn-Christian. Theoretical, Numerical and Experimental Investigation of the Flow in Rotor-Stator Cavities With Application to a Centrifugal Pump. Diss. Universitt Duisburg-Essen, Fakultt fr Ingenieurwissenschaften Maschinenbau und Verfahrenstechnik Institut fr Energieund Umweltverfahrenstechnik, 2011.

[16] Reinert, Jrgen, Ansgar Brockmeyer, and Rik WAA De Doncker. "Calculation of losses in ferro-and ferrimagnetic materials based on the modified Steinmetz equation." IEEE Transactions on Industry applications 37.4 (2001): 1055-1061. 